\title{
Respiratory and Hemodynamic Changes in Patients with Chronic Thromboembolic Pulmonary Hypertension 1 Year after Pulmonary Endarterectomy
}

\author{
Masato Sato, MD, PhD, Motomi Ando, MD, PhD, Kan Kaneko, MD, PhD, Yoshiro Higuchi, MD, PhD, \\ Hiroshi Kondo, MD, PhD, Kiyotoshi Akita, MD, PhD, Michiko Ishida, MD, PhD, and Yasushi Takagi, MD, PhD
}

We reviewed the results of thromboembolectomy, which was performed for the treatment of chronic thromboembolic pulmonary hypertension (CTEPH), 1 year after the operation. We obtained hemodynamic and respiratory data of 60 patients from the 112 patients who were operated at our institute. The hemodynamic parameters such as mean pulmonary arterial pressure (PAP), pulmonary vascular resistance (PVR), and cardiac index (CI) were significantly improved after the operation, and this improvement of pulmonary hemodynamics persisted even a year after the operation. A significant improvement in gas exchange was observed immediately after the operation and a further elevation in the partial pressure of oxygen in arterial blood $\left(\mathrm{PaO}_{2}\right)$ was observed 1 year after the operation. (*English Translation of $\mathrm{J}$ Jpn Coll Angiol 2012; 52: 53-58)

Keywords: chronic thromboembolic pulmonary hypertension, pulmonary endarterectomy, hemodynamic and respiratory outcome

\section{INTRODUCTION}

$\mathrm{C}$ hronic thromboembolic pulmonary hypertension (CTEPH) resists medical treatments, and pulmonary endarterectomy is the only effective radical treatment presently available. ${ }^{1-3)}$ At our facility, this procedure has been performed preferentially in patients with CTEPH since 2001, with marked respiratory and hemodynamic improvements immediately after surgery in many patients. After discharge, the respiratory and hemodynamics have been carefully followed up by admitting the patients after 1,3 , and 5 years. In this study, we examined whether or not the satisfactory respiratory and hemodynamic con-

Department of Cardiovascular Surgery, Fujita Health University, Toyoake, Aichi, Japan

Received: June 25, 2013; Accepted: July 2, 2013

Corresponding author: Masato Sato, MD, PhD. Otsuka Clinic,

Minami- Otsuka Ace Building, 3-34-6-401, Minami-Otsuka,

Toshima-ku, Tokyo 170-0005, Japan

Tel: +81-3-3984-2246, Fax: +81-3-3984-8812

E-mail: buhichan520@yahoo.co.jp

*This article is English Translation of J Jpn Coll Angiol 2012; 52: 53-58. ditions immediately after surgery were maintained after 1 year.

\section{SubJects ANd Methods}

Of the 112 patients with CTEPH who underwent pulmonary endarterectomy at our institute between August 2001 and September 2010, 60 who were successfully discharged were admitted to our institute for examination after about 1 year, and selected as the subjects. They consisted of 12 males and 48 females, with a mean age of 54.8 years. The data concerning the respiratory and hemodynamics obtained by right heart catheterization, echocardiography, pulmonary perfusion scintigraphy, and blood tests before, after (immediately before discharge), and 1 year after surgery were comparatively evaluated. Statistical analyses were performed by the t-test and $\chi^{2}$-test at the $\mathrm{p}<0.05$ level of significance.

Surgical indications: Similarly to Jamieson, et al., surgery was indicated when: 1) The mean pulmonary artery pressure (PAP) was $\geq 30 \mathrm{mmHg}$ and pulmonary vascular resistance (PVR) was $\geq 300$ dyne $\cdot \mathrm{sec} \cdot \mathrm{cm}^{-5}, 2$ ) the proximal 
Table 1 Peri-operative data $(n=60)$

\begin{tabular}{lc}
\hline Age (years) & $54.8 \pm 9.9$ \\
Gender (Male/Female) & $12 / 48$ \\
IVC filter (n) & 28 \\
Thrombophilia (n) & 3 (APS: 3 ) \\
PCPS induction (n) & 11 (Proximal type: 6 , Distal type: 5 ) \\
Distal type (n) & 14 \\
Operation time (min) & $405 \pm 68.7$ \\
Total circulatory arrest time (min) & $56.9 \pm 14.6$ \\
ICU stay (days) & $12.1 \pm 11.0$ \\
Tracheostomy (n) & 2 \\
\hline
\end{tabular}

IVC filter: inferior vena cava filter; PCPS: percutaneous cardiopulmonary support; ICU: intensive care unit; APS: anti-phospholipid antibody syndrome

end of the thrombus was located at a surgically accessible site, and 3) there was no serious complication. ${ }^{1)}$ The morphology of pulmonary artery obstruction was examined by pulmonary arteriography, truncal computed tomography (CT), and pulmonary perfusion scintigraphy, and patients with obstruction only distal to the subsegmental arteries were excluded from surgical candidates. Surgery was indicated when the preoperative clinical condition was New York Heart Association (NYHA) III or above without shock, in principle. In patients who preoperatively showed exacerbation of respiratory and cardiovascular dynamics, surgery was performed after improving the condition by medical treatments, i.e., rest by hospitalization, oxygen administration, and drug therapy (epoprostenol drip infusion, oral administration of bosentan, sildenafil, etc.).

Surgical procedure: Surgery was performed using the method established by the San Diego Group. ${ }^{1,4)}$ The approach was made by a median sternotomy, extracorporeal circulation was established with blood inflow through the ascending aorta and outflow through the superior and inferior vena cava, the and blood was cooled until the core body temperature was reduced to $18^{\circ} \mathrm{C}$. Retractors were applied between the ascending aorta and superior vena cava, anterior aspect of the right main pulmonary artery was incised longitudinally, and the endarterectomy plane was identified. The ascending aorta was clamped, ante- and retrograde cardioplegic solutions were infused, and, when the core body temperature reached $18^{\circ} \mathrm{C}$, endarterectomy was performed toward the segmental artery using special forceps. Circulatory arrest was maintained for 15 minutes at a time, and the periods of circulatory arrest were interposed by 10 -minute systemic perfusion, during which the ante- and retrograde cardioplegic solutions were infused. After endarterectomy of the right pulmonary artery was completed by several circulatory arrests, the systemic circulation was resumed, and the incision was closed by suturing. Next, the heart was retracted to the right and inferiorly using a heart net, the left main pulmonary artery was incised, and endarterectomy was performed by intermittent circulatory arrests similarly to the right pulmonary artery. After the completion of endarterectomy, the systemic circulation was restored, and the incision was closed while normalizing the body temperature. After recovery of the normal body temperature, weaning from the cardiopulmonary bypass was attempted. In patients showing marked pulmonary hypertension persisting even with the use of catecholamines, vasodilators, etc., a pulmonary artery pressure nearly equal to the systemic blood pressure, preventing the maintenance of the hemodynamics, or severe airway bleeding, PCPS was applied before weaning from extracorporeal circulation and closing the sternal incision.

\section{Results}

Table 1 shows the perioperative data of the 60 patients. There were 14 patients with distal-type CTEPH with lesions located primarily distal to the segmental arteries. Postoperative PCPS was applied to 11, of whom 6 had proximal-type CTEPH. The mean operation time was 405 minutes, and the mean total cardiac arrest time was 56.9 minutes. The mean duration of intensive care unit (ICU) care was 12.1 days, and tracheotomy was performed in 2 patients who required long-term respiratory management.

Changes in the mean PAP (Fig. 1), PVR (Fig. 2), cardiac index (CI) (Fig. 3), partial pressure of oxygen under room air (Fig. 4), brain natriuretic peptide (BNP) (Fig. 5), and NYHA grade (Fig. 6) before, after (before discharge), and 1 year after surgery are presented. The mean pulmonary artery pressure was $49.1 \pm 11.8 \mathrm{mmHg}$ before surgery, 


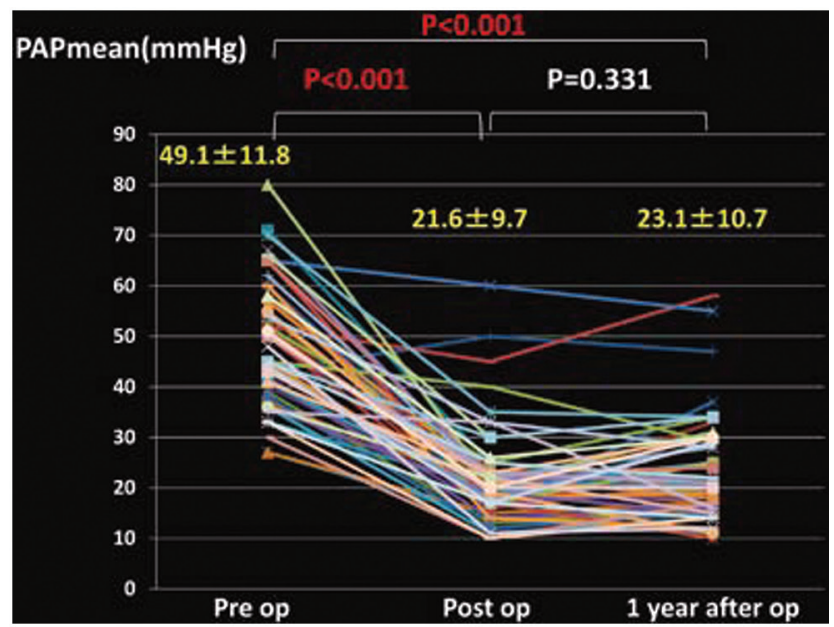

Fig. 1 Changes in pulmonary arterial pressure (PAP) (mean).

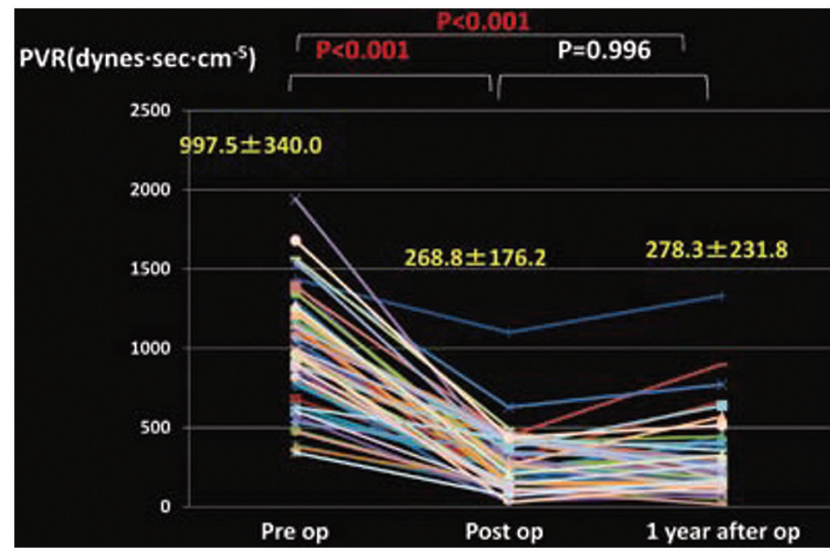

Fig. 2 Changes in pulmonary vascular resistance (PVR).

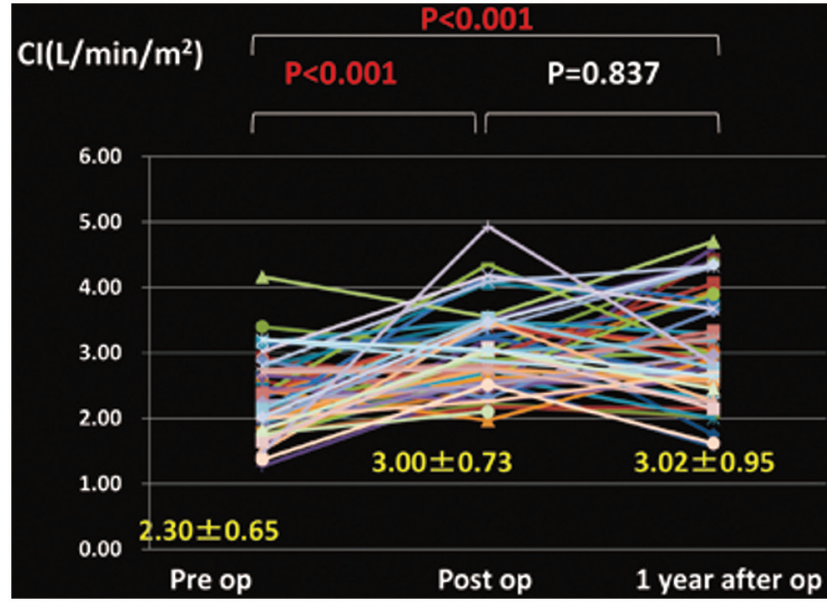

Fig. 3 Changes in cardiac index (CI).

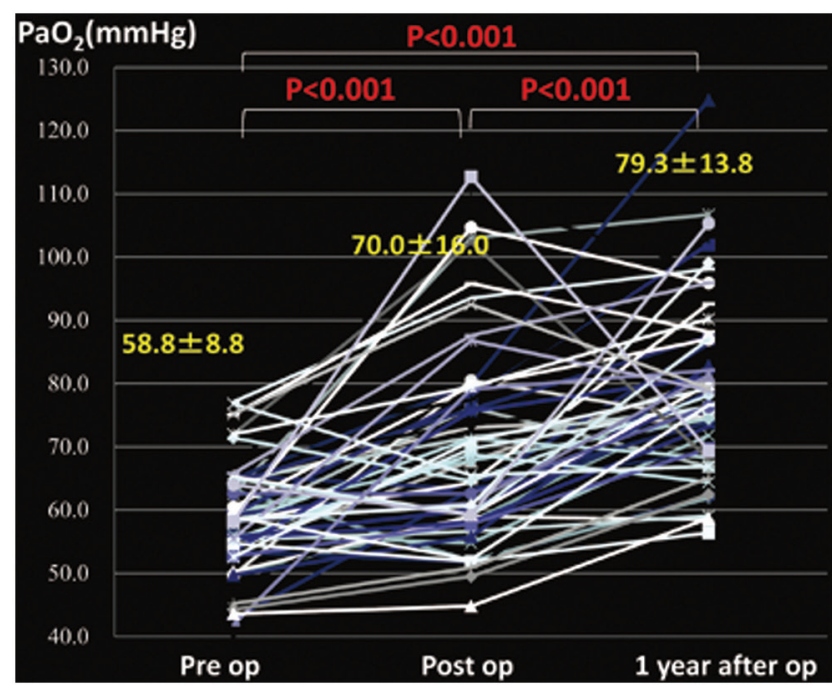

Fig. 4 Changes in $\mathrm{PaO}_{2}$ under room air.

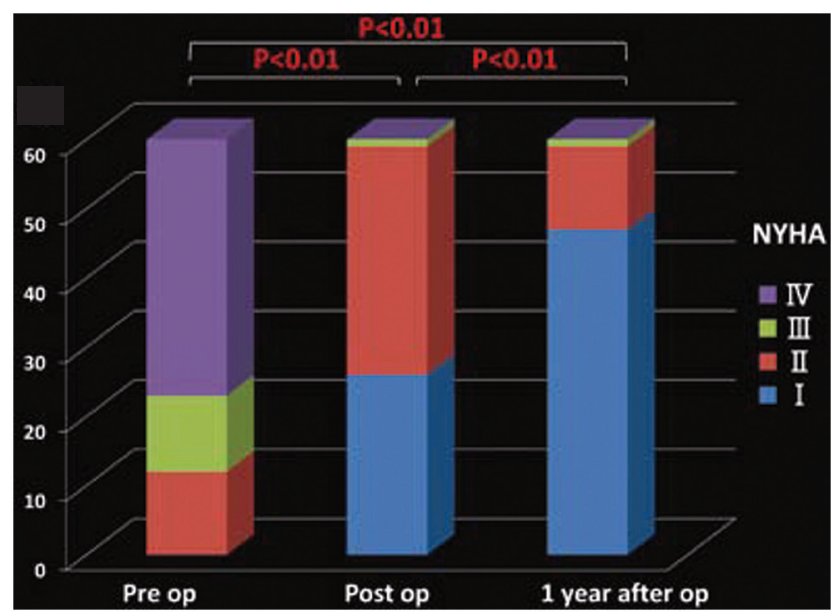

Fig. 6 Changes in New York Heart Association (NYHA) Class.

Fig. 5 Changes in brain natriuretic peptide (BNP). 
significantly decreased after surgery to $21.6 \pm 9.7 \mathrm{mmHg}$ ( $p<0.001$ ), and was $23.1 \pm 10.7 \mathrm{mmHg}$ after 1 year, showing no significant change. The pulmonary vascular resistance was $997.5 \pm 340.0$ dyne $\cdot \mathrm{sec} \cdot \mathrm{cm}^{-5}$ before surgery, decreased significantly after surgery to $268.8 \pm 176.2$ dyne. $\mathrm{sec} \cdot \mathrm{cm}^{-5}$ ( $\left.\mathrm{p}<0.001\right)$, and was $278.3 \pm 231.8$ dyne $\cdot \mathrm{sec} \cdot \mathrm{cm}^{-5} 1$ year after surgery, showing no significant change. The CI was $2.30 \pm 0.65 \mathrm{l} / \mathrm{min} / \mathrm{m}^{2}$ before surgery, significantly increased to $3.00 \pm 0.731 / \mathrm{min} / \mathrm{m}^{2}$ after surgery $(p<0.001)$, and was $3.02 \pm 0.951 / \mathrm{min} / \mathrm{m}^{2} 1$ year after surgery, showing no significant change. The partial pressure of oxygen in room air was $58.8 \pm 8.8 \mathrm{mmHg}$ before surgery, significantly increased to $70.0 \pm 16.0$ $\mathrm{mmHg}$ after surgery $(\mathrm{p}<0.001)$, and increased further to $79.3 \pm 13.8 \mathrm{mmHg} 1$ year after surgery $(\mathrm{p}<0.001)$. The blood BNP level was $371.5 \pm 382.2 \mathrm{pg} / \mathrm{ml}$ before surgery, significantly decreased after surgery to $91.6 \pm 74.0$ $\mathrm{pg} / \mathrm{ml}(\mathrm{p}<0.01)$, and significantly decreased again 1 year after surgery to $51.2 \pm 44.0 \mathrm{pg} / \mathrm{ml}(\mathrm{p}<0.01)$. The number of patients classified as NYHA III or higher was 48 before surgery but significantly decreased to 1 after surgery, and the percentage of patients classified as NYHA I increased further after 1 year.

\section{Discussion}

The values of hemodynamic parameters such as the mean pulmonary artery pressure, pulmonary vascular resistance, and CI improved markedly after (before discharge) compared with before surgery. No further improvement was observed after 1 year, but a satisfactory state was maintained. However, the partial pressure of oxygen improved significantly after surgery and improved further after 1 year. While more than half of the patients required home oxygen therapy at discharge, those requiring the therapy decreased after 1 year. It has been reported that improvements in hemodynamics are observed from shortly after pulmonary endarterectomy, but that there is a time lag before improvements in the partial pressure of oxygen, and Tanabe et al. ${ }^{5)}$ reported that improvements in the gas exchange capacity required 6-24 months after surgery. There have been the following reports concerning the reason for this delay: 1) Direct effects of surgery: Hypoxemia is caused early after surgery by impaired diffusion due to ventilation-perfusion imbalance and pulmonary edema as a result of a reduced respiratory function due to sternotomy, postoperative atelectasis, and pleural adhesion. 2) Vascular steal phe- nomenon: On pulmonary perfusion scintigraphy early after surgery, the areas in which the blood flow has been restored by endarterectomy are delineated as hyperperfused areas, but non-endarterectomized areas appear as new hypoperfused areas (vascular steal phenomenon), but this phenomenon gradually disappears on long-term postoperative follow-up with resolution of hypoxia. 3) Intrapulmonary shunts are increased. However, there has also been a report that dyspnea was resolved with a decrease in dead space ventilation after endarterectomy, but that the decrease in dead space ventilation was not directly correlated with changes in the hemodynamics. $\left.{ }^{6}\right)$

Of the subjects in this study, 8 patients showed persisted pulmonary hypertension: the mean pulmonary artery pressure before discharge was $\geq 30 \mathrm{mmHg}$. Distal type was 3, and PCPS was used in 2 with distal-type and 1 with proximal-type CTEPH. While all patients were alive 1 year after surgery, pulmonary hypertension was exacerbated compared with the preoperative state in 2 . The surgical indications of distal-type CTEPH must be carefully evaluated, ${ }^{7)}$ but surgery is not very effective, and pulmonary hypertension persists in some patients with proximal-type CTEPH, making treatment of this disease difficult.

The 60 subjects of this study were all discharged alive, but surgery-related deaths were observed in $12(9.8 \%)$ of the 112 patients who underwent surgery during this period. This number includes those treated shortly after the initiation of this procedure at our institute, and surgery-related deaths decreased to 2 out of the 74 patients treated after 2006, when the modifications of the perioperative management and surgical procedure were introduced. These outcomes are almost same as those reported by the San Diego Group ( $<4 \%$ in the recent 200 cases $)^{3)}$ or other facilities $(6.9 \%-24 \%){ }^{8-11)}$

\section{Conclusion}

The respiratory and hemodynamic conditions of CTEPH patients improved by pulmonary endarterectomy were maintained, and the partial pressure of oxygen was further improved after 1 year.

\section{Disclosure Statement}

None of the authors has any conflicts of interest to disclose. 


\section{REFERENCES}

1) Jamieson SW, Auger WR, Fedullo PF, et al. Experience and results with 150 pulmonary thromboendarterectomy operations over a 29 -month period. J Thorac Cardiovasc Surg 1993; 106: 116-26; discussion 126-7.

2) Ando M, Yamashita M, Sato M, et al. Surgical treatment for chronic pulmonary thromboembolism. J Jpn Surg Soc 2005; 106: 252-7. (in Japanese)

3) Thistlethwaite PA, Kaneko K, Madani MM, et al. Technique and outcomes of pulmonary endarterectomy surgery. Ann Thorac Cardiovasc Surg 2008; 14: 274-82.

4) Daily PO, Dembitsky WP, Iversen S. Technique of pulmonary thromboendarterectomy for chronic pulmonary embolism. J Card Surg 1989; 4: 10-24.

5) Tanabe N, Okada O, Nakagawa Y, et al. The efficacy of pulmonary thromboendarterectomy on long-term gas exchange. Eur Respir J 1997; 10: 2066-72.

6) van der Plas MN, Reesink HJ, Roos CM, et al. Pulmonary endarterectomy improves dyspnea by the relief of dead space ventilation. Ann Thorac Surg 2010; 89: $347-52$.
7) Sato M, Ando M, Yamashita M, et al. Postoperative use of a percutaneous cardiopulmonary support device after pulmonary thromboendarterectomy for Chronic Thromboembolic Pulmonary Hypertension. Jpn J Phlebol 2009; 20: 37-42.

8) Mellemkjaer S, Ilkjaer LB, Klaaborg KE, et al. Pulmonary endarterectomy for chronic thromboembolic pulmonary hypertension. Ten years experience in Denmark. Scand Cardiovasc J 2006; 40: 49-53.

9) Corsico AG, D'Armini AM, Cerveri I, et al. Longterm outcome after pulmonary endarterectomy. Am J Respir Crit Care Med 2008; 178: 419-24.

10) Saouti N, Morshuis WJ, Heijmen RH, et al. Longterm outcome after pulmonary endarterectomy for chronic thromboembolic pulmonary hypertension: a single institution experience. Eur J Cardiothorac Surg 2009; 35: 947-52; discussion 952.

11) Matsuda H, Ogino H, Minatoya $K$, et al. Long-term recovery of exercise ability after pulmonary endarterectomy for chronic thromboembolic pulmonary hypertension. Ann Thorac Surg 2006; 82: 1338-43; discussion 1343. 